\title{
The Use of Kembara Rindu Novel by Habiburrahman El Shirazy for Teaching Materials Indonesian For Foreign Speakers
}

\author{
Fatmawati ${ }^{1}$, Andayani ${ }^{2}$, and Raheni Suhita ${ }^{3}$ \\ ${ }^{123}$ Universitas Sebelas Maret \\ 1fatmawati45_8@student.uns.ac.id, 2bu_anda09@yahoo.co.id, \\ ${ }^{3}$ raheni_suhita@yahoo.com
}

\begin{abstract}
The BIPA program is increasingly in demand. As from 1974, this program has been attended by 8.514 participants from 126 friendly countries. Of course this number is not a small number. The increasing number of BIPA students and the development of the BIPA program must also be followed by improving the quality of learning. One way to improve the quality of BIPA learning is by utilizing teaching materials that are contextual and relevant to the needs of BIPA learners according to their level of authority. This study aims to describe the use of the Kembara Rindu novel by Habiburrahman El Shirazy for BIPA teaching materials. The use of novels as BIPA teaching materials refers to the objectives and learning indicators in the BIPA textbook "Sahabatku Indonesia" level C2 unit 7 regarding the material to review films and books. This type of research is a qualitative study using Miles and Huberman's interactive data analysis methods, namely data reduction, data display, and conclusions drawing and verification. The results of this study reveal that the use of the Kembara Rindu novel for BIPA teaching materials has two benefits. The first, BIPA learners can improve their language skills, especially reading and writing skills. Second, BIPA students can get to know and know Indonesian culture.
\end{abstract}

Keywords: BIPA, kembara rindu novel, teaching materials.

\section{PENDAHULUAN}

Cakupan pembelajaran bahasa Indonesia sangat luas, salah satunya ialah pembelajaran BIPA [1]. Bahasa Indonesia makin giat dipelajari oleh warga negara Asing (WNA) untuk beberapa keperluan, salah satunya ialah untuk keperluan akademik. Umumnya, warga negara asing yang mempelajari bahasa Indonesia untuk keperluan akademik ialah akademisi. Mereka mempelajari bahasa Indonesia secara langsung di Indonesia sebelum menempuh pendidikan formal pada universitas dan program studi yang mereka tuju [2]. Meningkatnya jumlah pemelajar BIPA didukung oleh program darmasiswa yang diselenggarakan oleh Kementerian Pendidikan dan Kebudayaan (Kemdikbud). Pada tahun 2019 terdapat 673 peserta darmasiswa dari berbagai negara. Program ini dimulai sejak tahun 1974 dan telah diikuti sebanyak 8.514 peserta yang berasal dari 126 negara sahabat. Jumlah peserta darmasiswa dapat dilihat dari data darmasiswa.kemdikbud.go.id. 
Di Indonesia program BIPA telah dilaksanakan di hampir seluruh perguruan tinggi ternama Indonesia, baik yang berstatus negeri maupun swasta [3]. Mengacu pada perkembangan BIPA yang meningkat ini, harus selaras dengan peningkatan kualitas pembelajarannya. Upaya-upaya untuk meningkatkan kualitas pembelajaran BIPA ialah melalui pemanfaatan media pembelajaran yang aktual dan kontekstual. Selain itu, upaya lainnya ialah perlunya pengembangan dalam pembelajaran BIPA [4]. Dengan demikian, perlu adanya bahan ajar BIPA yang kompherensif sebagai penyeimbang besarnya minat penutur asing untuk mempelajari bahasa Indonesia [5].

Karya sastra merupakan salah satu bentuk seni yang menggunakan bahasa sebagai mediumnya, baik secara lisan maupun tulisan. Dengan demikian pemilihan karya sastra sebagai salah satu jenis bahan ajar dalam pembelajaran BIPA merupakan suatu hal yang bisa diterima. Pemilihan karya sastra sebagai bahan ajar juga disebabkan oleh kebiasaan membaca karya sastra di mancanegara telah dimulai sebagai kegiatan wajib di sekolah menengah [6]. Dengan demikian, pemilihan karya sastra sebagai bahan ajar untuk pembelajaran BIPA tidak akan mengalami kesulitan dalam proses pelaksanaanya. Mengingat bahwa bacaan sastra tidak seperti membaca buku-buku ilmiah lain yang membutuhkan analisis mendalam dan bersifat ilmiah. Membaca karya sastra juga menjadi hal yang menarik dalam proses pembelajaran. Salah satu bentuk karya sastra ialah, novel.

Penelitian ini bertujuan untuk mendeskripsikan pemanfaatan novel Kembara Rindu karya Habiburrahman El Shirazy untuk bahan ajar BIPA. Pemilihan novel ini sebagai bahan ajar mengacu pada beberapa pertimbangan yakni, novel Kembara Rindu terdiri atas 266 halaman, artinya tidak terlalu tebal. Dengan demikian pemelajar BIPA tidak akan merasa berat membaca novel ini. Alasan lainnya ialah, novel ini tergolong novel populer yang mana bahasa yang digunakan adalah bahasa-bahasa yang umum digunakan dalam komunikasi sehari-hari. Novel ini juga mengandung banyak aspek kehidupan seperti pendidikan, ekonomi, sosial dan budaya. Hal demikian memungkinkan pemelajar dapat mengetahui banyak istilah dan kosa kata yang terdapat novel tersebut.

\section{METODE PENELITIAN}

Penelitian ini adalah penelitian kualitatif deskriptif. Penelitian ini bermaksud untuk memahami fenomena tentang apa yang dialami oleh subjek penelitian secara holistik dengan cara memanfaatkan pelbagai metode ilmiah [7]. Sumber data penelitian ini adalah novel karya Habiburrahman El Shirazy yakni Kembara Rindu. Data dikumpulkan dengan menggunakan metode kajian pustaka, cara ini digunakan untuk menemukan dan menelaah dari berbagai sumber, baik buku-buku maupun jurnal-jurnal ilmiah. Dalam Penelitian ini, metode analisis data menjadi serangkaian teknik penelitian sebagai perpanjangan dari pikiran manusia. Fungsinya ialah untuk mencari hubungan antar data yang tidak pernah dinyatakan sendiri oleh data yang bersangkutan [8]. Analisis data dalam penelitian ini menggunakan analisis data model interaktif Miles dan Huberman yang meliputi: pertama, reduksi data. Tahapan ini berkaitan dengan pengelompokkan data yang sesuai dengan permasalahan dalam penelitian. Kedua, sajian data. Hal ini berkaitan dengan cara data disajikan. Penelitian ini menguraikan data dalam bentuk narasi. Ketiga menarik kesimpulan dan verifikasi. Tahap ini berkaitan dengan proses menyimpulkan berdasarkan serangkaian fakta atau rincian informasi yang tersaji dalam penyajian data dan memverifikasi [9]. 


\section{HASIL DAN PEMBAHASAN}

\subsection{Konteks Materi}

Pembelajaran BIPA memiliki karakteristik tersendiri, tetapi tak bisa dipungkiri bahwa pada kenyataanya proses pembelajaran BIPA dan proses pembelajaran bahasa pada umumnya berkaitan dan tidak dapat dipisahkan [10]. Dengan demikian, maka pembelajaran BIPA pada hakikatnya berkaitan dengan komponen, prinsip dan peran dasar pembelajarannya. Dalam pelaksanaanya, kurikulum dan bahan ajar BIPA telah disusun oleh Pemerintah. Kurikulum tersebut dijadikan sebagai pedoman atau panduan dalam pelaksanaan pembelajaran BIPA. Kurikulun yang telah disusun itu tidak hanya ditujukkan untuk program BIPA yang ada di dalam negeri tetapi juga untuk BIPA di luar negeri. Terdapat tiga tingkat (level) dalam program BIPA, yakni tingkat dasar, menengah dan mahir [11].

Umumnya, dalam pemilihan dan penyusunan bahan ajar BIPA perlu memerhatikan aspek kebutuhan pemelajar. Dengan demikian sebelum penyusunan bahan ajar, tahap awal yang mesti dilakukan ialah membuat analisis kebutuhan (needs analysis). Dalam tahapan analisis kebutuhan pemelajar, maka pertimbangan khususnya adalah memerhatikan bagaimana latar belakang, tujuan, minat, budaya, dan tingkat kemahiran berbahasa pemelajar. Informasi terkait hal-hal itu sangat urgen untuk diketahui, sebab sentral pembelajaran BIPA dan komponennya ialah kebutuhan pemelajar [12]. Dengan memperhatikan beberapa aspek tersebut, materi yang akan disajikan bersifat kontekstual dan relevan dengan kebutuhan pemelajar. Hal tersebut merupakan salah satu faktor untuk mencapai tujuan pembelajaran BIPA.

Seluruh aspek yang menjadi konten kurikulum yang harus dikuasai siswa sesuai dengan kompetensi dasar dalam rangka mencapai standar kompetensi disebut dengan materi ajar atau bahan ajar [13]. Kaitannya dengan materi ajar BIPA ini, maka ada beberapa faktor yang mesti diperhatikan saat mengembangkan materi ajar yakni adanya hubungan materi ajar dengan tujuan pembelajaran secara aspektual maupun global, setara dengan taraf kemampuan pemelajar, harus dapat mengembangkan dan membangkitkan motivasi pemelajar, relevan dengan pemahaman dan aktual, adanya pelibatan pemelajar secara aktif baik dengan berpikir sendiri maupun dengan melakukan berbagai kegiatan, kesesuaian dengan metodik yang ditetapkan dan diambil dari berbagai peristiwa atau fakta kebahasaan serta pemakaian bahasa Indonesia secara nyata [14]. Selain beberapa faktor tersebut, materi BIPA yang digunakan juga harus sesuai dengan tingkatan penguasaan pemelajar BIPA. Hal demikian berdasar pada asumsi bahwa pemilihan materi yang tepat akan membuat suasana belajar lebih menyenangkan, pemelajar BIPA akan lebih antusias dalam mempelajari bahasa Indonesia [15].

Secara umum, materi BIPA harus ada tema yang mengikat keseluruhan materi. Tema-tema tersebut harus sesuai dengan kompetensi peserta didik. Pilihan temapun harus disesuaikan dengan konteks dan minat belajar siswa. Topik yang dapat dijadikan materi ajar BIPA adalah kesusastraan. Topik ini ada pada tingkatan mahir atau tingkat lanjut. Dalam buku ajar BIPA "Sahabatku Indonesia" dikenal dengan istilah tingkat C1 dan C2. Materi tentang kesusastraan berkaitan dengan mengulas film dan buku ada pada tingkat C2. Dengan demikian pemberian materi tentang membuat resensi terhadap sebuah karya sastra hanya akan diberikan pada pemelajar tingkat mahir. Pada tingkat ini, pemelajar BIPA sudah banyak menguasai kosa kata, dan sudah memiliki kemampuan membaca dan menulis yang tinggi dbandingkan dengan penguasaan keterampilan mereka saat berada pada level dasar dan madya. 


\subsection{Novel dalam Pembelajaran BIPA}

Sastra memiliki keunggulan sebagai pendekatan kepada pemelajar asing, karena di dalam karya sastra terdapat berbagai macam cerita dengan berbagai variasi bahasa, terdapat dialogdialog yang kadang tersemat di dalamnya. Dengan demikian, pemelajar dapat memperkaya penguasaan kosa katanya, serta mengetahui pola komunikasi yang dilakukan oleh orang Indonesia. Salah satu contoh karya sastra adalah novel. Pemanfaatan novel sebagai salah satu jenis karya sastra pada pembelajaran BIPA didasarkan pada tujuan yakni: 1) untuk memperoleh pengetahuan sastra dengan memberikan konsep tentang teori, sejarah, dan macam-macam sastra; dan 2) untuk memberikan pengalaman sastra dengan melakukan membaca, mengapresiasi karya sastra, serta menciptakan karya sastra [16]. Acap kali novel menyingkap pedebatan atau pelbagai masalah yang terkait dengan budaya (culture), persoalan moral, pendidikan, politik, hingga realitas keagamaan yang tumbuh dan berkembang di suatu daerah tertentu. Dengan demikian, tidaklah berlebihan jika dikatakan bahwasanya novel ialah potret suatu daerah, gambaran masyarakatnya, dan permasalahan hidup dan kehidupan di suatu masyarakat.

Pada umunya pengajar sastra, kadang-kadang merasa sulit menentukan novel mana yang relevan diajarkan. Meski demikian, pemilihan novel haruslah tetap memperhatikan aspek penting. Menurut Endraswara dalam bukunya yang berjudul Metode \& Teori Pengajaran Sastra, setidaknya ada dua hal yang mesti diperhatikan, yakni kevalidan dan kesesuaian. Kevalidan berkaitan dengan kriteria dan aspek-aspek kesastraan, sedangkan kesesuaian berhubungan dengan subjek didik sebagai konsumen novel [17]. Mempelajari sastra artinya mempelajari bahasa dalam praktik. Pangkal dari pembelajaran sastra ialah realisasi bahwasanya setiap karya pada dasarnya merupakan himpunan kata yang harus ditelusuri, diteliti, dianalisis dan diintegrasikan [18]. Dalam pembelajaran terkait sastra ini, pemelajar BIPA diharuskan untuk membaca salah satu novel, yakni novel Kembara Rindu karya Habiburrahman El Shirazy. Selanjutnya pemelajar akan membuatkan resensi novel yang telah dibaca. Dengan demikian, selain membaca novel, siswa akan dilatih untuk menulis dengan durasi panjang dan mampu untuk memberikan penilaian pada sebuah novel.

\subsection{Novel Kembara Rindu}

Novel sebagai bahan pengajaran memiliki kelebihan, salah satunya ialah novel cukup ringan dan mudah untuk dinikmati pemelajar sesuai dengan tingkat kemampuannya masingmasing secara personal. Namun perlu diketahui juga bahwasanya tingkat kemampuan tiap individu tidaklah sama. Dengan demikian novel untuk bahan ajar ini, mengambil sastra populer, yakni novel Kembara Rindu. Sebab novel ini mudah dibaca dan dipahami. Novel ini memuat kosa kata yang ringan dan populer yang umunya dipakai dalam komunikasi bahasa Indonesia. Hal ini berangkat dari pernyataan Abraham Kaplan bahwasanya sastra populer terletak pada manfaat yang akan diberikan kepada pembaca sastra tersebut, bukan terletak pada ketidakmampuannya memenuhi tuntutan kritik [19]. Berdasarkan hal itu, maka pemilihan novel Kembara Rindu dalam pengajaran BIPA ini menekankan pada aspek-aspek yang akan memberikan manfaat bagi kualitas pengajaran BIPA.

Novel Kembara Rindu terbit pertama pada September 2019, penulisnya ialah Habiburrahman El Shirazy yang pada tahun 2019 dinobatkan sebagai Tokoh Perbukuan Islam 2019 oleh Panitia Islamic Book Fair (IBF) Jakarta. Novelis yang kerap disapa Kang Abik ini juga telah diganjar dengan pengharagaan internasional. Novel ini merupakan novel dwilogi yang bercerita tentang kehidupan Ainur Ridho atau yang biasa dengan nama Ridho. Ia 
merupakan anak yatim piatu di Wae Meranti, Lampung. Ia menempuh pendidikan sekolah dasar dan sekolah menengah pertama di Lampung, lalu melanjutkan pendidikan menengah atas di pondok pesantren yang diasuh oleh Kiyai Nawir.

Perjalanan hidupnya dimulai dari pesan kakeknya yang bernama kakek Jirun. Ia tak boleh meninggalkan pesantren sebelum gurunya yang memerintahkannya untuk pulang. Selama bertahun-tahun menjadi khadim di pesantren Sidawangi, suatu ketika Kiyai Nawir memerintahkannya untuk kembali ke kampung halamannya dan membangun kampungnya, sekaligus untuk menjaga putri bungsu kiyai Nawir yang akan pergi ke Lampung untuk melanjutkan pendidikan tinggi di UNILA.

Setelah sampai di kampung halamannya, Ridho yang sudah yatim piatu harus menjadi tulang punggung keluarga menggantikan Syifa, sepupunya yang kini sudah putus sekolah. Hari-hari yang sulit ia lewati. Tak sedikit yang mencemoohnya karena jauh-jauh sekolah ke Jawa dan pulang hanya bekerja sebagai penjual di kampung. Karena kesibukannya berjualan iapun tak sempat untuk merawat masjid yang ada di depan rumahnya. Suatu ketika, kiyai Shobron, putra pertama Kiyai Nawir yang tinggal di Lampung menjenguknya lalu membantunya dengan meminjamkan dana untuk membuka usaha. Kehidupan Ridho sedikit lebih maju, ia mulai bisa mengatur waktu untuk berusaha berdagang di pasar tempat Syifa menjual gorengan di pagi hari, lalu memakmurkan masjid, dan mengisinya dengan mengajar anak-anak sekitarnya mengaji.

Tantangan hidup tak hanya dihadapi oleh Ridho, tetapi juga Syifa, sepupu Ridho yang juga anak yatim piatu. Ia terlahir dari seorang perempuan bernama Nur Lailah dan Syahril Abrar, pengusaha kaya di Lampung yang sudah menikah dan punya dua orang anak. Kehidupan Syifa diliputi ujian yang luar biasa, setelah ibunya meninggal dunia. Ia harus bisa bertahan hidup bersama adiknya yang masih balita, Lukman. Ia diasuh oleh kakek dan neneknya. Sehari-hari ia harus menjual gorengan untuk memenuhi kebutuhan keluarga, dan harus menelan pil pahit, putus sekolah saat tamat SMP. Suatu ketika di saat ada pasar malam, ia berdagang di malam hari. Hampir saja di lecehkan oleh dua orang preman saat hendak kembali pulang. Untung saja ada Ridho yang kebetulan melewati jalan tersebut. Novel Kembara Rindu ini memuat banyak persoalan dalam kehidupan. Lewat novel ini pemelajar BIPA dapat dapat mempelajari kehidupan sosial masyakarat Lampung khusunya di Wae Meranti, budaya, agama, ekonomi, serta pendidikan yang terkandung dalam karya sastra tersebut.

\subsection{Manfaat Sastra dalam Pengajaran BIPA}

Pengajaran sastra dalam pendidikan memiliki empat manfaat, yaitu: 1) membantu keterampilan berbahasa; 2) mengetahui budaya; 3) mengembangkan cipta rasa; dan 4) membentuk watak. Pemanfaatan novel Kembara Rindu karya Habiburrahman El Shirazy untuk bahan ajar ini berkaitan dengan pemberian materi tentang kesusastraan Indonesiaan, yang mana tujuannya ialah agar pembelajaran BIPA menjadi lebih menarik dan mereka lebih mengenal Indonesia [18]. Dengan demikian pembelajaran ini tidak hanya mementingkan aspek bahasa, tetapi juga aspek-aspek lain [20], contohnya ialah aspek budaya Indonesia. Dalam pengajaran BIPA ditemukan dua manfaat novel Kembara Rindu sebagai bahan ajar BIPA, berikut uraianya:

Pertama, membantu keterampilan berbahasa khususnya keterampilan membaca dan menulis. Pemelajar dapat meningkatkan keterampilan membaca dengan cara membaca suatu karya sastra, yakni novel Kembara Rindu karya Habiburrahman El Shirazy. Tahapan membaca novel ini tidak sekadar di dalam kelas saja. Sebab membaca novel memerlukan 
waktu yang cukup lama, sehingga pengajar harus memberikan tugas membaca novel ini sebagai tugas mandiri yang akan dikerjakan di luar kelas. Dengan demikian pembacaan novel menjadi lebih efektif. Selain itu pemelajar dapat membaca novel ini secara mendalam, karena pemelajar bisa sambil mencatat kosa kata baru yang ia temukan dalam novel tersebut. Setelah meningkatkan keterampilan membaca, selanjutnya ialah pemelajar dapat meningkatkan keterampilan menulis. Hal ini berdasar pada tugas lanjutan setelah membaca, yakni menuliskan pendapat pribadi tentang novel yang telah dibaca.

Kedua, pemelajar BIPA dapat mengetahui budaya Indonesia. Pemahaman lintas budaya dalam pembelajaran BIPA itu sudah pasti terjadi. Sebab pemelajar BIPA adalah mereka yang memiliki latar belakang budaya yang berbeda dengan orang Indonesia. Budaya berkaitan dengan cara hidup manusia di suatu tempat. Budaya ialah daya dari budi yang berupa cipta, karsa, dan rasa [21]. Budaya adalah semua jenis aktivitas manusia dan hasilnya yang berpola, baik yang terindera maupun tidak terindera. Pemahaman budaya sangat penting bagi pemelajar BIPA sebagai bekal hidup mereka untuk berinteraksi dengan masyarakat Indonesia sehari-hari. Suatu karya sastra dipengaruhi oleh budaya tempat karya sastra itu diciptakan. Penganut teori mimesis berpandangan bahwa pada prinsipnya karya seni sebagai pencerminan, peniruan atau pembayangan realitas [22]. Hal demikian sejalan dengan pernyataan Purnomo yang menyatakan bahwa karya sastra seperti apapun bentuknya, ia merupakan karya budaya, sehingga karya sastra merupakan teks budaya masyarakat [23]. Sebagai teks budaya, maka karya sastra merepresentasikan masyarakatnya dan segala sistem yang melingkupinya baik kekuasaan, kepentingan, nilai-nilai, ideologi, sosial ekonomi dan sebagainya. Berdasarkan pernyataan itu, maka membaca karya sastra tentu akan membaca konteks budaya. Dengan demikian pemelajar BIPA yang membaca karya sasatra akan mengetahui konteks budaya orang Indonesia [24].

\section{SIMPULAN}

Belajar sastra pada dasarnya adalah belajar bahasa dalam praktik. Dengan demikian novel Kembara Rindu karya Habiburrahman El Shirazy dapat diajdikan sebagai bahan ajar dalam pembelajaran BIPA. Bahan ajar yang dipilih disesuaikan dengan standar kompetensi, kompetensi dasar, tujuan dan indikator dalam pengajaran BIPA. Novel sebagai bahan ajar diberikan pada pemelajar yang telah menamatkan pelajaran ditingkat dasar dan madya. Novel diperuntukkan untuk pemelajar BIPA tingkat mahir. Memanfaatkan novel Kembara Rindu karya Habiburrahman El Shirazy sebagai bahan ajar dalam pembelajaran BIPA yakni pada materi tentang mengulas film dan buku yang terdapat dalam tingkat $\mathrm{C} 2$ unit 7, buku "Sahabatku Indonesia". Pemanfaatan novel Kembara Rindu untuk bahan ajar ini memiliki dua manfaat, yakni meningkatkan keterampilan berbahasa khususnya keterampilan membaca dan menulis, manfaat keduanya ialah pemelajar BIPA dapat mengenal dan mengetahui budaya Indonesia.

\section{REFERENCES}

[1] A. Kusmiatun, Mengenal Bipa (Bahasa Indonesia Bagi Penutur Asing) Dan Pembelajarannya. Yogyakarta: K-Media, 2016.

[2] M. Yahya, A. -, And K. Saddhono, "Tendensi Kesalahan Sintaksis Bahasa Tulis Pembelajar Bipa (Sebuah Kajian Kesalahan Berbahasa)," Dialekt. J. Bahasa, Sastra, Dan Pendidik. Bhs. Dan Sastra Indones., Vol. 5, No. 1, Pp. 1-20, 2018.

[3] R. F. Azizah, "Pembelajaran Bahasa Indonesia Bagi Penutur Asing (Bipa) Program Cls (Critical Language Scholarship) Di Fakultas Sastra Universitas Negeri Malang 
Tahun 2012," Pp. 1-13, 2012.

[4] C. Megawati, "Pengembangan Media Pembelajaran Bipa Tingkat Menengah Melalui E-Book Interaktif Di Program Incountry Universitas Negeri Malang Tahun 2014," Nosi, Vol. 2, No. 1, Pp. 62-70, 2014.

[5] A. E. Prasetiyo, "Pengembangan Bahan Ajar Bipa Bermuatan Budaya Jawa Bagi Penutur Asing Tingkat Pemula," Pendidik. Bhs. Dan Sastra Indones. Fbs Unnes, Pp. $1-11,2015$.

[6] H. Nugroho, "Pendekatan Sastrawi Untuk Pembelajaran Bipa," Pp. 734-743, 2012.

[7] L. J. Moleong, Metode Penelitian Kualitatif, Revisi. Bandung: Pt. Remaja Rosdakarya, 2016.

[8] Faruk, Metode Penelitian Sastra: Sebuah Penjelajahan Awal. Yogyakarta: Pustaka Pelajar, 2017.

[9] M. B. Miles And M. A. Huberman, Analisis Data Kualitatif: Buku Sumber Tentang Metode-Metode Baru. 2014.

[10] P. Andayani, M. Pd, L. Gilang, And S. Sn, "The Effectiveness Of Integrative Learning Based Textbook Toward The Local Culture Comprehension And Indonesian Language Skill Of Foreign Students," Int. J. Humanit. Soc. Sci., Vol. 5, No. 10, Pp. 197-207, 2015.

[11] Y. Purwiyanti, "Strategi Komunikasi Pemelajar Bahasa Indonesia Bagi Penutur Asing (Bipa) Asal Filipina," Ranah J. Kaji. Bhs., Vol. 6, No. 2, Pp. 160-179, 2017.

[12] S. Arumdyahsari And G. Hs, Widodo Susanto, "Pengembangan Bahan Ajar Bahasa Indonesia Bagi Penutur Asing ( Bipa ) Tingkat Madya," J. Pendidik. Teor. Penelitian, Dan Pengemb., Vol. 1, No. 5, Pp. 828-834, 2016.

[13] L. Muliastuti, Bahasa Indonesia Bagi Penutur Asing: Acuan, Teori, Dan Pendekatan Pengajaran. Jakarta: Yayasan Pustaka Obor Indonesia, 2017.

[14] I. Suyitno, Bahasa Indonesia Bagi Penutur Asing: Teori, Strategi, Aplikasi Pembelajarannya. Yogyakarta: Grafika Indah, 2005.

[15] Hertiki, "Pengajaran dan Pembelajaran BIPA di Perguruan Tinggi Polandia" Vol. 6, No. 2, Pp. 2-6, 2017.

[16] T. A. Nurhuda, H. J. Waluyo, And Suyitno, "Pemanfaatan Sastra Sebagai Bahan Ajar Pengajaran Bipa," 1st Educ. Lang. Int. Conf., Pp. 864-869, 2017.

[17] Endraswara, Metode \& Teori Pengajaran Sastra. Yogyakarta: Buana Pustaka, 2005.

[18] Rahmanto, Metode Pengajaran Sastra. Yogyakarta: Kanisius, 1988.

[19] R. Noor, M. Mutu, And P. Sastra, "Sastra Populer Dan Masalah Mutu Penelitian Sastra Di Perguruan Tinggi," J. Nusa, Vol. 12, No. 4, Pp. 265-275, 2017.

[20] K. Saddhono, "Kajian Sosiolingustik Pemakaian Bahasa Mahasiswa Asing Dalam Pembelajaran Bahasa Indonesia Untuk Penutur Asing (Bipa) Di Universitas Sebelas Maret," J. Kaji. Linguist. Dan Sastra, Vol. 24, No. 2, Pp. 176-186, 2012.

[21] Koenjaraningrat, Pengantar Ilmu Antropologi. Jakarta: Aksara Baru, 1980.

[22] Teeuw, Sastra Dan Ilmu Sastra: Pengantar Teori Sastra. Jakarta: Dunia Pustaka Jaya, 2015.

[23] M. H. Purnomo, "Menguak Budaya Dalam Karya Sastra: Antara Kajian Sastra Dan Budaya Mulyo Hadi Purnomo 75," J. Ilm. Kaji. Antropol., Pp. 75-82, 2006.

[24] K. Saddhono, "Integrating culture in Indonesian language learning for foreign speakers at Indonesian universities,” J. Lang. Lit., vol. 6, no. 2, 2015. 